\title{
Treatment of metal (loid) contaminated solutions using iron-peat as sorbent: is landfilling a suitable management option for the spent sorbent?
}

\author{
Alfreda Kasiuliene $^{1}$ D $\cdot$ Ivan Carabante $^{1} \cdot$ Prosun Bhattacharya $^{2} \cdot$ Jurate Kumpiene $^{1}$ \\ Received: 6 February 2019 / Accepted: 3 May 2019 / Published online: 23 May 2019 \\ (C) The Author(s) 2019
}

\begin{abstract}
This study firstly aimed to investigate the potential of simultaneous metal (loid) removal from metal (oid) solution through adsorption on iron-peat, where the sorbent was made from peat and Fe by-products. Up-flow columns filled with the prepared sorbent were used to treat water contaminated with $\mathrm{As}, \mathrm{Cu}, \mathrm{Cr}$, and $\mathrm{Zn}$. Peat effectively adsorbed $\mathrm{Cr}$, $\mathrm{Cu}$, and $\mathrm{Zn}$, whereas approximately $50 \%$ of inlet As was detected in the eluent. Iron-sand was effective only for adsorbing $\mathrm{As}$, but $\mathrm{Cr}$, $\mathrm{Cu}$, and $\mathrm{Zn}$ were poorly adsorbed. Only iron-peat showed the simultaneous removal of all tested metal (loid)s. Metal (loid) leaching from the spent sorbent at reducing conditions as means to assess the behaviour of the spent sorbent if landfilled was also evaluated. For this purpose, a standardised batch leaching test and leaching experiment at reducing conditions were conducted using the spent sorbent. It was found that oxidising conditions, which prevailed during the standardised batch leaching test, could have led to an underestimation of redox-sensitive As leaching. Substantially higher amounts of As were leached out from the spent sorbents at reducing atmosphere compared with oxidising one. Furthermore, reducing environment caused As(V) to be reduced into the more-toxic As (III).
\end{abstract}

Keywords Arsenic $\cdot$ Metals $\cdot$ Trace elements $\cdot$ Sorption $\cdot$ Landfill leachate $\cdot$ Low redox

\section{Introduction}

Arsenic (As) contaminates soil and groundwater in various areas throughout Sweden due to past industrial activities, such as glass works and wood impregnation, and other metals, such as chromium $(\mathrm{Cr})$, copper $(\mathrm{Cu})$, and zinc $(\mathrm{Zn})$, occur as cocontaminants at varying concentrations in some of these sites (Bhattacharya et al. 2002; Lov et al. 2017; Hagner et al. 2018).

Arsenic is commonly removed from contaminated water by adsorption onto reactive media. Iron $(\mathrm{Fe})$ oxides have an

Responsible editor: Tito Roberto Cadaval Jr

Alfreda Kasiuliene

alfreda.kasiuliene@1tu.se

1 Department of Civil, Environmental and Natural Resources Engineering, Lulea University of Technology,

SE-97187 Lulea, Sweden

2 Department of Sustainable Development, Environmental Science and Engineering, Royal Institute of Technology, Teknikringen 76, SE-100 44 Stockholm, Sweden affinity for arsenates and are known to be effective and potentially inexpensive adsorbents for use in treating Ascontaminated water (Carabante et al. 2014; Ahmad et al. 2017). To avoid clogging of filters (Mohan and Pittman 2007) and to overcome low hydraulic permeability (Theis et al. 1992), Fe-containing filters are commonly produced by coating Fe oxides onto a bulk material, such as sand (Devi et al. 2014; Wang et al. 2017; Callegari et al. 2018) or activated carbon (Yurum et al. 2014; Mondal and Garg 2017), where there are advantages of using activated carbon instead of sand because it also targets other contaminants.

Peat is among the numerous natural materials that has a metal adsorption capacity (Chaney and Hundemann 1979), and it can be coated with Fe oxides without employing an activation step (in contrast to many of the materials used to produce activated carbon). As shown by Kasiuliene et al. (2018), combining peat with Fe results in a versatile sorbent that can simultaneously target both cationic and anionic contaminants. This preparation provides the potential of utilising by-products and/or waste materials when manufacturing the adsorbent. Peat as waste can occur from the production of energy and electricity, or from agriculture, horticulture, and 
water filtration processes, and iron by-products can be obtained from the steel industry. In this respect, utilisation of byproducts and waste materials is an environmentally sustainable practice that contributes to a circular economy.

Landfilling is often the preferred option for spent adsorbents that bear inorganic contaminants (Mohan and Pittman 2007). The most common method to determine landfill type for waste acceptance is the compliance batch leaching test when waste is exposed to a leachant for $24 \mathrm{~h}$ under aerobic conditions (Council Directive 1991/31/EC, Annex II). The purpose of the test is to simulate the leaching potential of the waste placed in landfill. However, landfills normally provide anaerobic conditions, unlike the aerobic conditions that are present in the standardised leaching test, and thus the standardised leaching test will not always adequately address the actual leaching potential of investigated waste.

In a low redox environment, arsenates $(\mathrm{As}(\mathrm{V}))$ can be reduced to arsenites (As (III)), which are more mobile and toxic (Corvin et al. 1999). Whereas, Cr (VI) can undergo very rapid changes to poorly soluble $\mathrm{Cr}$ (III) if redox potential drops (Hausladen and Fendorf 2017). Zinc, and especially $\mathrm{Cu}$, usually remains insoluble as precipitates in a landfill environment (Jambeck et al. 2008). The solubility of metal (loid)s can change due to water infiltration and the influx of oxygen $\left(\mathrm{O}_{2}\right)$ into the landfill site, and due to changes in biological activity (Bozkurt et al. 2000). This necessitates leachate treatment leading to a perpetual cycle. Thus, when evaluating metal (loid) releases from landfills over a long-time, abiotic factors such as redox potential need to be seriously considered.

This study firstly aimed to investigate the potential of simultaneous metal (loid) removal from solution through adsorption on iron-peat, where the sorbent was made from peat and Fe by-products. Up-flow columns filled with the prepared sorbent were used to treat water contaminated with $\mathrm{As}, \mathrm{Cu}, \mathrm{Cr}$, and $\mathrm{Zn}$. The second aim of this study was to evaluate metal (loid) leaching from the spent sorbent at reducing conditions, with the objective of assessing the behaviour of the spent sorbent if it were to be landfilled. For this purpose, a standardised batch leaching test and leaching experiment at reducing conditions were conducted.

\section{Material and methods}

\section{Preparation of sorbents}

Heat-treated peat powder was obtained from Geogen Produktion AB, Sweden. The company produces heattreated peat granulates as an environmentally compatible oiladsorption agent, and particles smaller than $2 \mathrm{~mm}$ are discarded during its production. Ferric-ferrous hydrosol provided by Rekin, Lithuania, was used to coat the peat. The hydrosol was a colloidal suspension of $\mathrm{Fe}$ (II) and Fe (III) hydrated compounds; it is produced from Fe waste during the process of electrolysis and acts as a binder for wastewater pollutants. The peat powder was then thoroughly mixed with the ferric-ferrous hydrosol at a ratio of $1 w: 1 w$, with a small amount of water added for homogenisation.

To verify that both peat and $\mathrm{Fe}$ are required for the simultaneous removal of cations and anions, in the following experiments, two control sorbents were used: i) sand, with a particle size of $0.5-1.0 \mathrm{~mm}$, coated with ferric-ferrous hydrosol $(1 w: 4 w)$ and ii) uncoated peat. Hereinafter, coated peat powder is referred to as 'iron-peat', coated sand as 'iron-sand', and control peat powder as 'peat'.

All sorbents were then dried at $35^{\circ} \mathrm{C}$ for $24 \mathrm{~h}$ before being used as up-flow column fillers. Total solids (TS) and loss on ignition (LOI) were subsequently determined following standard procedures (ISO 11465: 1993); the specific surface area was determined according to the Brunauer-Emmett-Teller (BET) nitrogen $\left(\mathrm{N}_{2}\right)$ adsorption isotherm technique (where $\mathrm{N}_{2}$ adsorption was conducted at $77 \mathrm{~K}$ ) using an ASAP 2020 micropore analyser (Micrometrics).

\section{Column adsorption experiment}

A known mass of dry peat (110 g), iron-peat (134 g), and ironsand $(546 \mathrm{~g})$ sorbents was sealed into high-density polyethylene columns $(45 \mathrm{~mm} \times 200 \mathrm{~mm})$ with a bed volume (BV) of $0.32 \mathrm{~L}$. The inlet hose was connected to a container holding a metal (loid) solution, which is hereafter referred to as the 'inlet solution', and the outlet hose was connected to a sample collection bottle that was air-tight and dark to avoid $\mathrm{Fe}$ oxidation. The experiment was performed in triplicate. The flow rate was set at $1.2 \mathrm{~mL} \mathrm{~min}^{-1}$. The eluate was sampled daily, and electrical conductivity (EC) (CDM 10, Radiometer Copenhagen), $\mathrm{pH}$ (pH 340, WTW), and Eh (CDM 10, Radiometer Copenhagen) were measured immediately after sampling. Subsamples for metal (loid) analysis were filtered through $0.45-\mu \mathrm{m}$ cellulose filters, acidified and analysed using inductively coupled plasma optical emission spectrometry (ICP-OES) (Optima 8300, Perkin-Elmer). The experiment was stopped after 60 days; the columns were then opened and the spent sorbents were laid out to dry at $35^{\circ} \mathrm{C}$ for $24 \mathrm{~h}$. The total metal (loid) concentrations in the sorbents before and after the filter experiment were determined with ICP-OES after wet digestion with aqua regia in a microwave (CEM Mars 5) at $190{ }^{\circ} \mathrm{C}$.

The metal (loid) solution was prepared from analytical grade chemicals: $\mathrm{NaH}_{2} \mathrm{AsO}_{4}$ (Honeywell Riedel-de Haën $\mathrm{AG}, 99 \%$ ), $\mathrm{K}_{2} \mathrm{Cr}_{2} \mathrm{O}_{7}$ (VWR International, 99.9\%), $\mathrm{CuCl}_{2}$. $2 \mathrm{H}_{2} \mathrm{O}$ (Merck, 99\%), and $\mathrm{ZnCl}_{2}$ (Merck, 98\%). Metal (loid) salts were dissolved into $0.1 \mathrm{M}$ potassium nitrate $\left(\mathrm{KNO}_{3}\right.$, VWR International, 100\%) solution, and the solution $\mathrm{pH}$ was set to 5.0 using $0.1 \mathrm{M}$ hydrochloric acid $(\mathrm{HCl}$, Merck, $37 \%$ ). Initial metal (loid) concentrations in the solution were determined using ICP-OES, and detection limits were 
$0.002 \mathrm{mg} \mathrm{L}^{-1}$ for $\mathrm{As} ; 0.001 \mathrm{mg} \mathrm{L}^{-1}$ for $\mathrm{Cr}, \mathrm{Cu}$, and $\mathrm{Zn}$; and $0.014 \mathrm{mg} \mathrm{L}^{-1}$ for Fe. The inlet solution contained $0.88 \pm$ $0.07 \mathrm{mg} \mathrm{L}^{-1}$ of As and $4.1 \pm 0.4 \mathrm{mg} \mathrm{L}^{-1}$ of $\mathrm{Cr}, \mathrm{Cu}$, and $\mathrm{Zn}$.

\section{Standardised leaching test}

A batch leaching test at a liquid-to-solid $(\mathrm{L} / \mathrm{S})$ ratio $=10$, following procedure described in the Council Decision 2003/33/ EC, was performed with spent sorbents that were obtained after conducting the column adsorption experiment. Samples were leached with ultra-pure water for $24 \mathrm{~h}$ using an end-overend rotator, then filtered and immediately analysed for $\mathrm{pH}$, EC, and Eh. Metal (loid) concentrations were determined using ICP-OES. A total organic carbon analyser (TOC-L series, Shimadzu) was used to determine the dissolved carbon (DC) content of the leachates. The detection limits for dissolved organic carbon (DOC) and for dissolved inorganic carbon (DIC) were $4 \mu \mathrm{g} \mathrm{L}^{-1}$.

\section{Leaching test at reducing conditions}

Spent sorbents and ultra-pure water at $\mathrm{L} / \mathrm{S}=10$ were sealed in 1-L glass bottles, and each replicate contained material from a separate column filter. Air in the bottles was exchanged with a methane $\left(\mathrm{CH}_{4}\right)$ and carbon dioxide $\left(\mathrm{CO}_{2}\right)$ gas mixture (50:50), and the bottles were placed in a dark cabinet at a temperature of $30 \pm 3{ }^{\circ} \mathrm{C}$. For sampling, $5-6 \mathrm{~mL}$ of the liquid was taken through a long needle inserted into the bottles, and the liquid was then measured immediately for $\mathrm{Eh}, \mathrm{pH}$, and EC. Subsamples were filtered, acidified, and analysed using ICPOES for metal (loid)s. Gasses in the bottles were supplemented with the $\mathrm{CH}_{4}$ and $\mathrm{CO}_{2}$ mixture after sampling the liquid. The gas composition $\left(\mathrm{CO}_{2}, \mathrm{O}_{2}, \mathrm{~N}_{2}\right.$, and $\left.\mathrm{CH}_{4}\right)$ was analysed at the end of the experiment using a gas chromatograph (Clarus $500)$ to verify the presence of reducing conditions. The detection limit was $100 \mathrm{ppm}$ for all gases. At the end of the experiment, the DOC content was determined as described in the "Standardised leaching test" section. The experiment lasted 200 days.

\section{Landfill gas production}

A biochemical methane potential (BMP) test was conducted in $100-\mathrm{mL}$ gas-tight serum bottles. The inoculated medium contained ultra-pure water, $2 \mathrm{~mL}$ of nutrients (Cederroth Nutrient Bloom containing $N_{\text {total }} 5.1 \mathrm{~g}$, potassium (K) $4.3 \mathrm{~g}$, calcium (Ca) $0.3 \mathrm{~g}$, phosphorus (P) $1 \mathrm{~g}$, sulphur (S) $0.4 \mathrm{~g}$, magnesium $(\mathrm{Mg}) 0.4 \mathrm{~g}$, Fe $35 \mathrm{mg}$, manganese $(\mathrm{Mn}) 20 \mathrm{mg}$, boron (B) $10 \mathrm{mg}$, Zn $3.0 \mathrm{mg}$, Cu $1.5 \mathrm{mg}$, and molybdenum (Mo) $0.4 \mathrm{mg}$; diluted at the ratio $1: 10$ ) per $1 \mathrm{~g}$ TS of the spent sorbent, and the inoculum (comprising sewage sludge after anaerobic digestion), which was added at a ratio of $3 w: 1 w$ of the volatile solids (VS). Calculation of VS was based on LOI (loss on ignition) analysis. Spent sorbent samples corresponding to $3 \mathrm{~g}$ of TS were added into the bottles together with the medium, and the bottles were sealed and incubated at $30^{\circ} \mathrm{C}$. Control bottles contained only the inoculated medium. The volume of gas produced was measured regularly. Since ironsand contained only a negligible fraction of VS $(<1 \%)$, it was not used in the BMP test because it was assumed that it would produce negligible amounts of landfill gases.

\section{Speciation analysis}

The $\mathrm{Cr}$ speciation in column adsorption samples was determined after 5 and after 50 days of the experiment as well as in the inlet solution. Determination of total $\mathrm{Cr}$ and $\mathrm{Cr}(\mathrm{VI})$ was done by ion chromatography, and $\mathrm{Cr}$ (III) was calculated from measured values. The detection limit for the total $\mathrm{Cr}$ and $\mathrm{Cr}$ (VI) was $0.4 \mu \mathrm{g} \mathrm{L}^{-1}$.

The As speciation in leachate samples was determined after the standardised batch leaching test and after the low redox experiment final sampling (after 200 days). Samples were analysed using liquid chromatography-inductively coupled plasma mass spectrometry. The detection limit for As (III), $\mathrm{As}(\mathrm{V})$, and dimethylarsinic acid (DMA) was $0.1 \mu \mathrm{g} \mathrm{L} \mathrm{L}^{-1}$; and that for methylarsonic acid (MMA) was $0.2 \mu \mathrm{g} \mathrm{L} \mathrm{L}^{-1}$.

Samples were kept frozen in plastic bottles prior to analysis. Both $\mathrm{Cr}$ and As speciation was done at an accredited laboratory (ALS Scandinavia).

\section{Statistics}

The data were processed using an analysis of variance (ANOVA) test with the software Minitab 18. A two-sample $t$ test $(p>0.05)$ was applied to differentiate between sample means.

\section{Results}

\section{Performance of column filters}

Three sorbents (peat, iron-peat, and iron-sand) were tested in up-flow columns for adsorption of contaminants from a solution. The metal (loid) contents of freshly prepared sorbents obtained prior to the adsorption experiment are presented in Table 1. Peat-based sorbents contained 21-22 mg As kg-1. Arsenic is an intrinsic element in peat, with concentrations ranging from $1 \mathrm{ng} \mathrm{L}^{-1}$ (Stepanova et al. 2015) up to $1800 \mathrm{mg} \mathrm{kg}^{-1}$ (Langner et al. 2013). Peat contained low levels of $\mathrm{Cr}$ and $\mathrm{Cu}$, which increased in iron-peat and iron-sand due to the ferric-ferrous hydrosol coating, where $\mathrm{Cu}$ and $\mathrm{Cr}$ may occur as impurities. Zinc was present both in peat and in sand. Uncoated peat contained approximately $10 \mathrm{~g} \mathrm{Fe} \mathrm{kg}^{-1}$, but the content of $\mathrm{Fe}$ in iron-peat (due to the coating) increased to 
Table 1 Average metal (loid) concentrations in the fresh and spent sorbents \pm standard deviation, $\mathrm{mg} \mathrm{kg}^{-1} \mathrm{dw}(n=3)$

\begin{tabular}{llllll}
\hline Material & As & Cr & $\mathrm{Cu}$ & $\mathrm{Fe}$ & $\mathrm{Zn}$ \\
\hline Fresh peat & $21.2 \pm 0.8$ & $3.07 \pm 0.12$ & $<0.2$ & $12.316 \pm 241$ & $30.1 \pm 3.1$ \\
Fresh iron-peat & $21.1 \pm 1.9$ & $16.4 \pm 1.2$ & $28.2 \pm 0.3$ & $56.082 \pm 1463$ & $31.4 \pm 2.8$ \\
Fresh iron-sand & $<0.4$ & $20.4 \pm 2.3$ & $32.1 \pm 2.2$ & $32.527 \pm 1927$ & $44.0 \pm 5.5$ \\
Spent peat & $451 \pm 71$ & $4132 \pm 606$ & $4374 \pm 941$ & $12.788 \pm 354$ & $4456 \pm 447$ \\
Spent iron-peat & $1010 \pm 183$ & $4036 \pm 453$ & $3960 \pm 778$ & $54.956 \pm 2487$ & $3374 \pm 184$ \\
Spent iron-sand & $123 \pm 7$ & $232 \pm 18$ & $256 \pm 15$ & $31.069 \pm 1131$ & $122 \pm 17$ \\
\hline
\end{tabular}

$57 \mathrm{~g} \mathrm{~kg}^{-1}$. Peat sorbent had the lowest BET specific surface area $1.19 \pm 0.02 \mathrm{~m}^{2} \mathrm{~g}^{-1}$, followed by iron-sand at $1.40 \pm$ $0.01 \mathrm{~m}^{2} \mathrm{~g}^{-1}$, and iron-peat sorbent had the largest surface area of $2.16 \pm 0.03 \mathrm{~m}^{2} \mathrm{~g}^{-1}$.

Table 2 presents the average EC and $\mathrm{pH}$ values in the eluates determined throughout the column experiment, in addition to average Eh values at the beginning and end of the experiment. At the beginning of the experiment, $\mathrm{pH}$ slightly above 4 was observed in peat-based eluates; acidic $\mathrm{pH}$ is typical for peat. The $\mathrm{pH}$ was above 2 in the iron-sand eluate; low $\mathrm{pH}$ resulted from acidic ferric-ferrous hydrosol. After 3 weeks, the $\mathrm{pH}$ of all eluates increased, and became $5.3 \pm 0.2$ (on average) which is similar to the $\mathrm{pH}$ of the inlet solution. $\mathrm{EC}$ of the eluates remained at the same level as within the inlet solution $\left(10.9 \pm 0.1 \mathrm{mS} \mathrm{cm}^{-1}\right)$.

Figure 1 presents relative metal (loid) concentrations $(C /$ $C_{0}$ ) over the cumulative $\mathrm{L} / \mathrm{S}$ ratio. The $C / C_{0}$ value shows the ratio between the metal (loid) concentration determined in the eluent versus the concentration in the inlet. In case the $C / C_{0}$ ratio was higher than unity, desorption started to occur; thus, the eluent contained higher metal (loid) concentration than present in the inlet solution. Cumulative L/S ratio was chosen as a unit to express time line of the experiment. Weight of the solids (S) was fixed, whereas volume of the liquid (L) that passed through each column was increasing; therefore, the cumulative L/S ratio was increasing as well. Guideline values for the drinking water suggested by the World Health Organization (World Health Organization 2017) were used as breakthrough points, and relative $C_{\mathrm{WHO}} / C_{0}$ values are represented by the horizontal lines in Fig. 1. The columns were filled with the same sorbent volumes, but the masses differed. A large fraction of the iron-sand was inert, and it was assumed

Table 2 Average EC, Eh, and $\mathrm{pH}$ values in the eluates \pm standard deviation $(n=3)$

\begin{tabular}{lllll}
\hline Material & $\mathrm{EC}, \mathrm{mS} \mathrm{cm}^{-1}$ & $\mathrm{pH}$ & \multicolumn{2}{l}{$\mathrm{Eh}, \mathrm{mV}$} \\
\cline { 3 - 5 } & & & Start & End \\
\hline Peat & $10.7 \pm 0.4$ & $5.5 \pm 0.3$ & $253 \pm 4$ & $147 \pm 7$ \\
Iron-peat & $10.9 \pm 1.5$ & $5.1 \pm 0.3$ & $291 \pm 8$ & $163 \pm 2$ \\
Iron-sand & $10.9 \pm 1.2$ & $5.2 \pm 0.3$ & $521 \pm 5$ & $308 \pm 8$ \\
\hline
\end{tabular}

that the sand did not affect the adsorption of metal (loid)s. To simplify a graphical presentation of the adsorption curves, the iron-sand mass was normalised, where the mass of sand was subtracted from the mass of iron-sand.

When peat was used as a sorbent, WHO drinking water guideline for As $\left(10 \mu \mathrm{g} \mathrm{L}{ }^{-1}\right)$ was not met (Fig. 1a), and although the sorption capacity of $104 \mathrm{mg} \mathrm{As} \mathrm{g}^{-1}$ sorbent was maintained until $4.3 \mathrm{BV}$ of the contaminated solution was processed, the sorbent gradually lost its efficiency. When using iron-peat, it was possible to maintain a sorption capacity of $133 \mathrm{mg} \mathrm{As} \mathrm{g}^{-1}$ sorbent for $220 \mathrm{BV}$ before it began to lose efficiency and exceeded the WHO guideline value. Iron-sand showed a similar sorption capacity for $256 \mathrm{BV}$.

Throughout the experiment, peat showed a sorption capacity of $106 \mathrm{mg} \mathrm{Cr} \mathrm{g}^{-1}$ sorbent (Fig. 1b), but it was too weak to meet the WHO guideline value for $\mathrm{Cr}\left(50 \mu \mathrm{g} \mathrm{L}^{-1}\right)$. The average sorption capacity of iron-peat was $132 \mathrm{mg} \mathrm{Cr} \mathrm{g}^{-1}$ sorbent, and $245 \mathrm{BV}$ of the contaminated solution was processed below the WHO guideline value. However, when using iron-sand, it was possible to treat approximately $10 \mathrm{BV}$ below the WHO guideline value, until the sorbent gradually lost its $\mathrm{Cr}$ adsorption efficiency.

Peat-based sorbents adsorbed $\mathrm{Cu}$ (Fig. 1c) with $>99 \%$ efficiency, and $\mathrm{Cu}$ in the eluate did not exceed the WHO guideline value $\left(2 \mathrm{mg} \mathrm{L}^{-1}\right)$. The average sorption capacity of peat was $109 \mathrm{mg} \mathrm{Cu} \mathrm{g}^{-1}$ sorbent and that of iron-peat was $134 \mathrm{mg} \mathrm{Cu} \mathrm{g}^{-1}$ sorbent, whereas iron-sand showed a $\mathrm{Cu}$ removal efficiency lower than $90 \%$, with a decreasing tendency throughout the experiment.

No health-based guideline value has been proposed by WHO for $\mathrm{Zn}$ in drinking water. Peat and iron-peat adsorbed $\mathrm{Zn}$ with an efficiency of $>90 \%$ for 175 and 146 BV, respectively (Fig. 1d). The average sorption capacity of peat was $102 \mathrm{mg} \mathrm{Zn} \mathrm{g}^{-1}$ sorbent and that of iron-peat was $118 \mathrm{mg} \mathrm{Zn} \mathrm{g}^{-1}$, whereas iron-sand was ineffective in adsorbing $\mathrm{Zn}$. Furthermore, at the beginning of the column experiment, $\mathrm{Zn}$ was leached out from the sand.

The Fe concentrations in eluates from peat and iron-peat were below $0.2 \%$ of total $\mathrm{Fe}$, as determined in the fresh sorbents (Table 1). In the first litre of eluate from the iron-sand columns, the Fe concentration corresponded to $1.05 \%$ of the total Fe concentration in the fresh sorbent, whereas the concentration later decreased and remained below the detection limit throughout the experiment. 

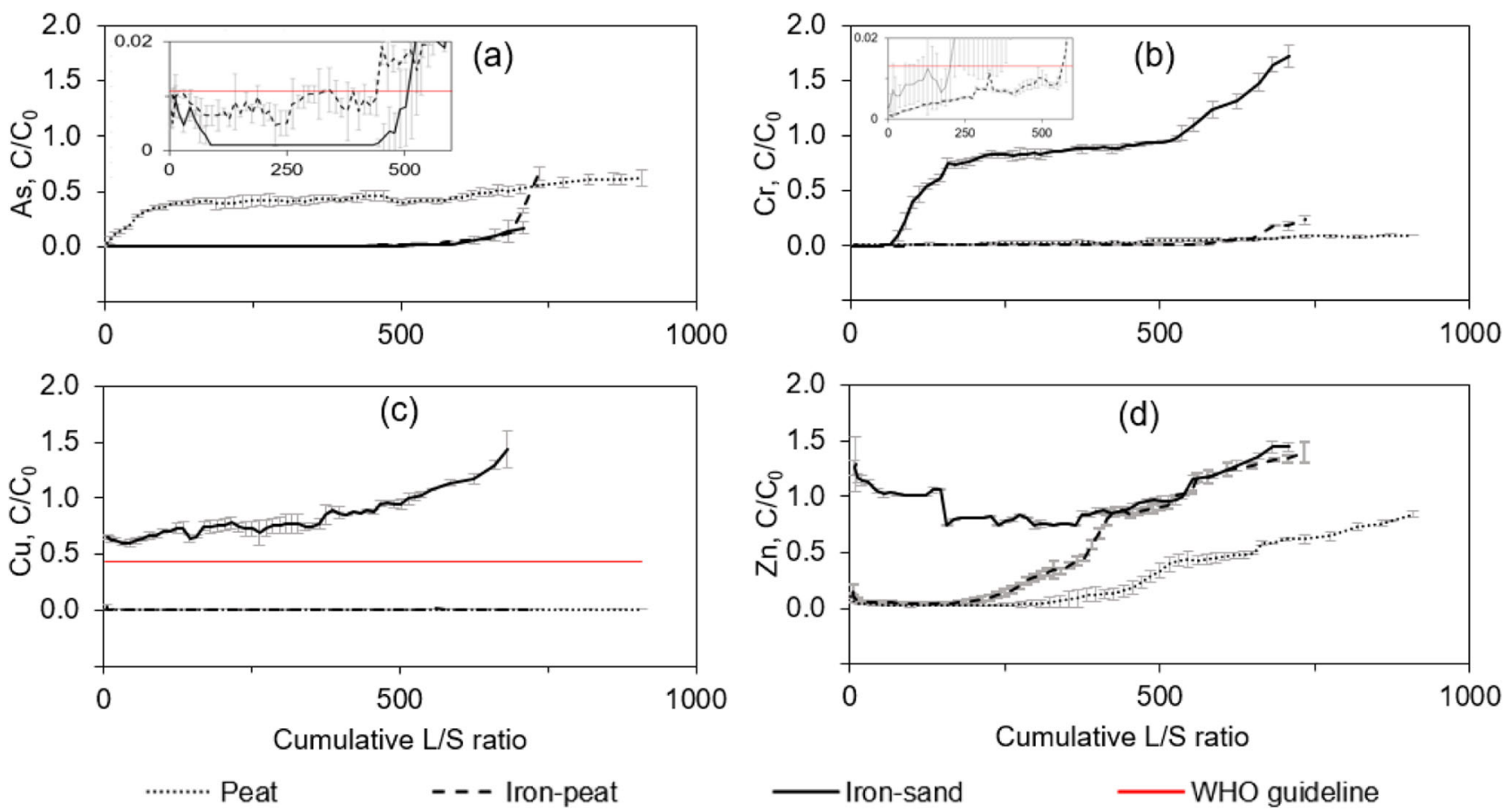

Fig. 1 Relative metal (loid) concentrations $\left(C / C_{0}\right)$ over the cumulative $\mathrm{L} / \mathrm{S}$ ratio during the column adsorption experiment. Error bars represent the standard deviation of the mean $(n=3)$. Inset figures in (a) and (b)

\section{Speciation of $\mathrm{Cr}$}

All $\mathrm{Cr}$ determined in the inlet solution appeared as $\mathrm{Cr}$ (VI). The same was observed for the eluate samples after the first 5 days; $\mathrm{Cr}$ (III) was below detection limits. After 50 days of the column experiment, eluates from spent peat contained $2.28 \mathrm{mg} \mathrm{L}^{-1}$ of total $\mathrm{Cr}$ and $\mathrm{Cr}$ (VI) corresponded to $84 \%$; eluates from iron-peat contained $1.31 \mathrm{mg} \mathrm{L}^{-1}$ of total $\mathrm{Cr}$ and $\mathrm{Cr}$ (VI) was 65\%; the $\mathrm{Cr}$ concentration in iron-sand eluates was $4.44 \mathrm{mg} \mathrm{L}^{-1}$ and no $\mathrm{Cr}$ (III) was detected.

\section{Characterisation of spent sorbents}

Loss on ignition analysis showed that spent peat and iron-peat sorbents contained $93.5 \pm 0.5 \%$ and $83.3 \pm 0.9 \%$ of VS, respectively, whereas the VS fraction in iron-sand was $<1 \%$. The biochemical methane potential estimates the amount of landfill gas produced during anaerobic degradation of organic waste fraction in landfill. Over a time-span of 150 days, the control produced $23-25 \mathrm{~mL}_{\text {gas }} \mathrm{g}^{-1} \mathrm{VS}$, whereas spent peat and ironpeat produced significantly less gases $\left(5-7 \mathrm{~mL}_{\text {gas }} \mathrm{g}^{-1} \mathrm{VS}\right)$.

Total metal (loid) concentrations in the spent sorbents are presented in Table 1.

\section{Standardised batch leaching test}

After the batch leaching test, the following Eh values were measured: spent iron-sand at $174 \pm 24 \mathrm{mV}$, spent peat at 188

\section{- Iron-sand}

show magnified curves at low concentrations of As and Cr. Straight vertical line denotes guideline values for drinking water proposed by WHO

$\pm 22 \mathrm{mV}$, and spent iron-peat at $210 \pm 37 \mathrm{mV}$. All leachates had a slightly basic $\mathrm{pH}$ of $7.6 \pm 0.3$, and the EC values of the spent peat and iron-peat leachates were similar (116 \pm $\left.13 \mu \mathrm{S} \mathrm{cm}^{-1}\right)$, whereas that of iron-sand leachates was $6.8 \pm$ $1.3 \mu \mathrm{S} \mathrm{cm}^{-1}$.

Metal (loid) concentrations determined in the leachates are presented in Table 3. Percentage of the total adsorbed metal (loid) concentrations (Table 1) is also presented in Table 3. The concentrations are compared with the limit values set for waste acceptance at different landfill types according to the Council Decision 2003/33/EC.

Nearly $10 \%$ of the adsorbed As was leached out from the spent peat sorbent, and the concentration in the leachate exceeded limit values for waste acceptable at hazardous waste landfills. However, leaching of $\mathrm{Cr}, \mathrm{Cu}$, and $\mathrm{Zn}$ remained $<$ $1 \%$, and was below the limits for non-hazardous waste landfills. Arsenic concentrations in the leachates of spent iron-peat and iron-sand sorbents defined that they could be deposited at landfills for hazardous waste. Iron-peat contained almost eight times more adsorbed As than iron-sand, but leaching from spent iron-peat was weaker. Leaching of $\mathrm{Cr}, \mathrm{Cu}$, and $\mathrm{Zn}$ from spent iron-peat were $<0.2 \%$ from the adsorbed content. Ironsand leached significantly higher concentrations of $\mathrm{Cu}$ and $\mathrm{Zn}$, and these concentrations were even more significant for $\mathrm{Cr}$ (1.6\% from adsorbed). Leaching of Fe was minimal, especially in the case of iron-sand.

In addition to metal (loid) s, leaching of DOC was also determined. The DOC value for spent peat was $589 \pm$ 
Table 3 Average metal (loid) concentrations ( $\mathrm{mg} \mathrm{kg}^{-1}, \mathrm{dw}$ ) leached from the spent sorbent during standardised batch leaching test \pm standard deviation $(n=3)$, percentage [\%] from adsorbed concentrations, and limit values for different landfill types $\left(\mathrm{mg} \mathrm{kg}^{-1}, \mathrm{dw}\right)$

\begin{tabular}{llllll}
\hline Material & As & $\mathrm{Cr}$ & $\mathrm{Cu}$ & $\mathrm{Fe}$ & $\mathrm{Zn}$ \\
\hline Peat & $42.8 \pm 7.9[9.5 \%]$ & $3.71 \pm 0.32[0.1 \%]$ & $7.17 \pm 1.15[0.2 \%]$ & $11.4 \pm 3.8[0.1 \%]$ & $2.36 \pm 0.47[0.1 \%]$ \\
Iron-peat & $9.88 \pm 4.6[1.0 \%]$ & $3.65 \pm 0.94[0.1 \%]$ & $6.96 \pm 2.83[0.2 \%]$ & $62.3 \pm 24.2[0.1 \%]$ & $1.99 \pm 0.85[0.1 \%]$ \\
Iron-sand & $2.38 \pm 1.9[1.9 \%]$ & $3.82 \pm 1.13[1.6 \%]$ & $2.28 \pm 4.31[0.9 \%]$ & $<0.001[<0.0001 \%]$ & $1.72 \pm 2.01[0.4 \%]$ \\
Non-hazardous waste & 2 & 10 & 50 & - & 50 \\
Hazardous waste & 25 & 70 & 100 & - & 200 \\
\hline
\end{tabular}

$39 \mathrm{mg} \mathrm{kg}^{-1}$, and for spent iron-peat, it was $417 \pm 75 \mathrm{mg} \mathrm{kg}^{-1}$. Both values were below the limits for non-hazardous waste landfills.

\section{Metal (loid) leaching at reducing conditions}

The gas composition analysis identified which samples had other than landfill gases present in the bottles (Table 4). The gas composition was only measured at the end of the low redox leaching experiment. In the case of the spent peat, only one replicate out of three (peat-1) had a $\mathrm{CH}_{4}$ atmosphere, but $\mathrm{O}_{2}$ represented $5 \%$ of the total gas composition. The ratios between $\mathrm{N}_{2}$ and $\mathrm{O}_{2}$ differed in all three replicates with the spent peat, which indicates the possible occurrence of other unidentified reactions. Methane was detected in all spent ironpeat replicates, and there was no detectable $\mathrm{O}_{2}$. In the case of spent iron-sand, only one replicate (iron-sand-3) contained $\mathrm{CH}_{4}$, but $\mathrm{O}_{2}$ was also present at a high concentration of $11 \%$. The ratio of $\mathrm{N}_{2}$ to $\mathrm{O}_{2}$ was similar in all bottles.

Determining the distinct gas composition in replicates of the same sample provided valuable insights into the different leaching behaviour of the analysed metal (loid)s. Changes in $\mathrm{pH}, \mathrm{Eh}$, and EC throughout the low redox experiment are presented in Fig. 2.

$\mathrm{pH}$ remained circum-neutral most of the time and showed no obvious influence from the gas composition (Fig. 2a, d, g).

Table 4 Gas composition (\%) in the low redox samples

\begin{tabular}{llllll}
\hline Material & $\mathrm{CO}_{2}$ & $\mathrm{O}_{2}$ & $\mathrm{~N}_{2}$ & $\mathrm{CH}_{4}$ & $\mathrm{~N}_{2} / \mathrm{O}_{2}$ \\
\hline Peat-1 & 31 & 5 & 32 & 33 & 6.40 \\
Peat-2 & 13 & 13 & 72 & 1 & 5.53 \\
Peat-3 & 20 & 6 & 74 & 0 & 12.3 \\
Iron-peat-1 & 31 & 1 & 33 & 35 & $\mathrm{nd}^{\mathrm{a}}$ \\
Iron-peat-2 & 28 & 1 & 55 & 16 & $\mathrm{nd}$ \\
Iron-peat-3 & 32 & 1 & 35 & 32 & $\mathrm{nd}$ \\
Iron-sand-1 & 1 & 20 & 77 & 1 & 3.85 \\
Iron-sand-2 & 1 & 21 & 76 & 2 & 3.61 \\
Iron-sand-3 & 13 & 11 & 40 & 36 & 3.63 \\
\hline
\end{tabular}

${ }^{\mathrm{a}}$ Not detected
Redox potential was approximately $200-270 \mathrm{mV}$ in peatbased spent sorbent samples at the beginning of the experiment (Fig. 2b, e), but it then gradually dropped to $40-60 \mathrm{mV}$ in replicates with a $\mathrm{CH}_{4}$ atmosphere. When $\mathrm{O}_{2}$ was present (peat-2, -3), Eh remained at a level similar to that at the beginning of the experiment, which indicated that a low redox condition had not been reached. Only iron-sand-3 maintained the $\mathrm{CH}_{4}$ atmosphere, whereas Eh decreased in all iron-sand replicates (Fig. 2h).

Electrical conductivity in the spent peat and iron-peat samples was approximately $190-240 \mu \mathrm{S} \mathrm{cm}^{-1}$ at the beginning of the experiment, and it increased continually thereafter (Fig. 2c, f). However, peat-1 showed a significantly higher EC than the other spent peat replicates. Spent iron-sand (Fig. 2i) underwent an EC increase from 47 to $105 \mu \mathrm{S} \mathrm{cm}^{-1}$.

The DOC content was not affected by gas composition. For spent peat, the DOC was $494 \pm 4 \mathrm{mg} \mathrm{kg}^{-1}$, and for spent ironpeat, it was $483 \pm 20 \mathrm{mg} \mathrm{kg}^{-1}$.

Metal (loid) concentrations in the leachates during the low redox experiment are shown in Fig. 3. The results are split depending on whether $\mathrm{CH}_{4}$ (or $\mathrm{O}_{2}$ ) existed in the replicates or not.

The concentrations of As (Fig. 3a) in all spent peat replicates were above the acceptance level for hazardous waste landfills (Table 3). After 200 days, 60\% of the adsorbed As had been leached out from the peat- 1 replicate, but a substantially lower amount (22\%) of adsorbed As had been leached out from peat- 2 and -3 by the end of the experiment. Leaching of As from the spent iron-peat was significantly lower than that from spent peat at reducing conditions (peat-1); although only $5.8 \%$ had been leached out at the end of the experiment, it was above the limit of disposal in hazardous waste landfills. Approximately $8 \%$ of the adsorbed As had been leached out from iron-sand-3, whereas only $3.8 \%$ of the adsorbed As had been leached at oxidising conditions (iron-sand-1, -2).

Leaching of $\mathrm{Cr}$ (Fig. 3b) from the peat-based spent sorbents was significantly higher at reducing conditions (peat-1 and iron-peat) in comparison with the peat-2, -3 replicates. In all cases, $\mathrm{Cr}$ leaching continuously increased, and by the end of the experiment, $\mathrm{Cr}$ concentrations of leachates were above the limit of hazardous waste landfills. However, an opposite trend was shown for $\mathrm{Cr}$ leaching from the spent iron-sand samples: 
Fig. $2 \mathrm{pH}$, Eh, and EC changes throughout the low redox experiment. A, b, c-represent triplicates with the spent peat; $d$, e, f-represent triplicates with the spent iron-peat; $\mathrm{g}, \mathrm{h}, \mathrm{i}$-represent triplicates with the spent ironsand
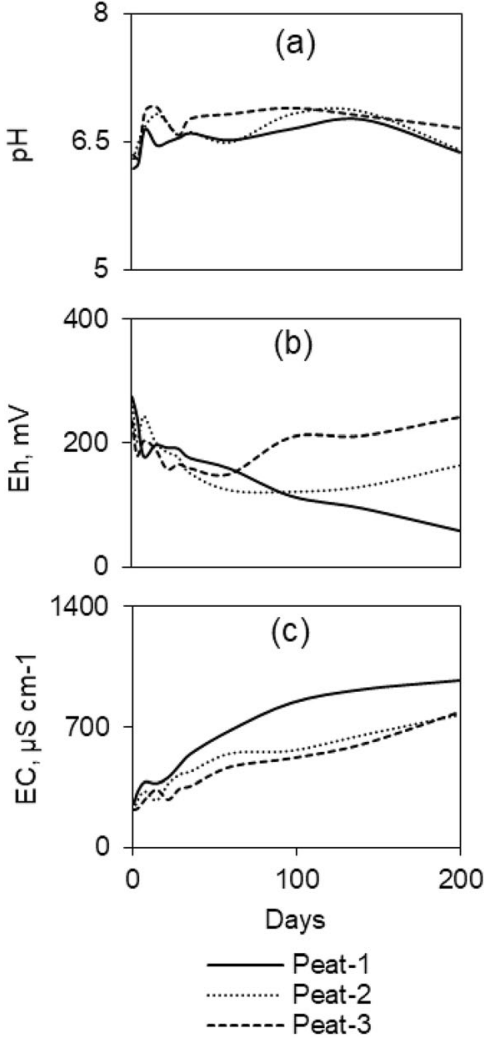
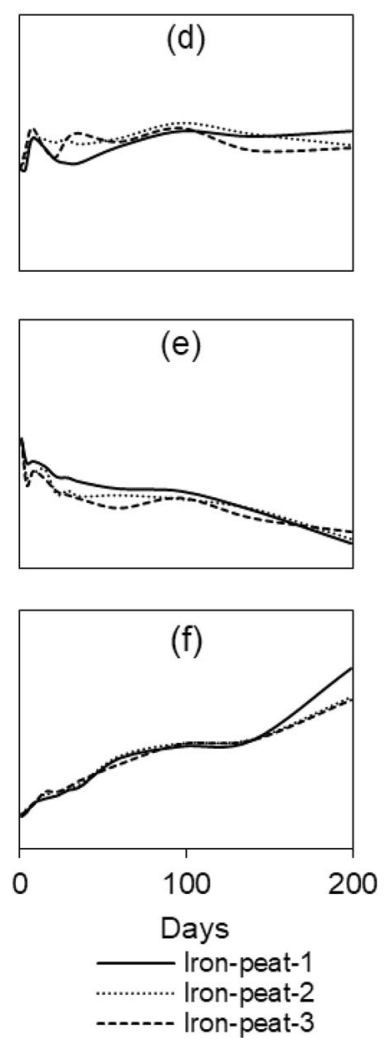

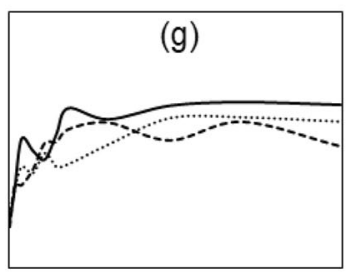

(h)

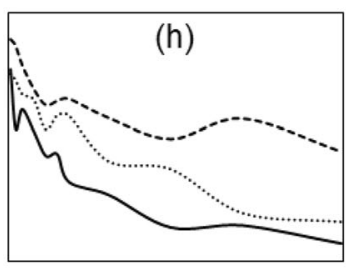

(i)

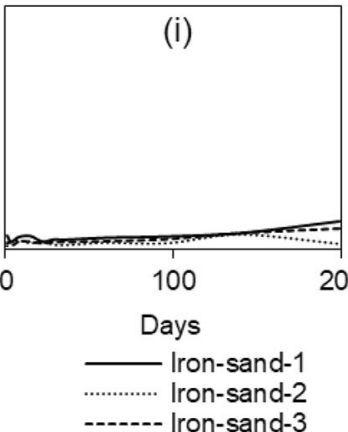

concentrations were higher at the beginning of the experiment than at the end. However, differences in $\mathrm{Cr}$ leaching between samples with $\mathrm{O}_{2}$ (iron-sand-1, -2) and those without it (ironsand-3) were insignificant.
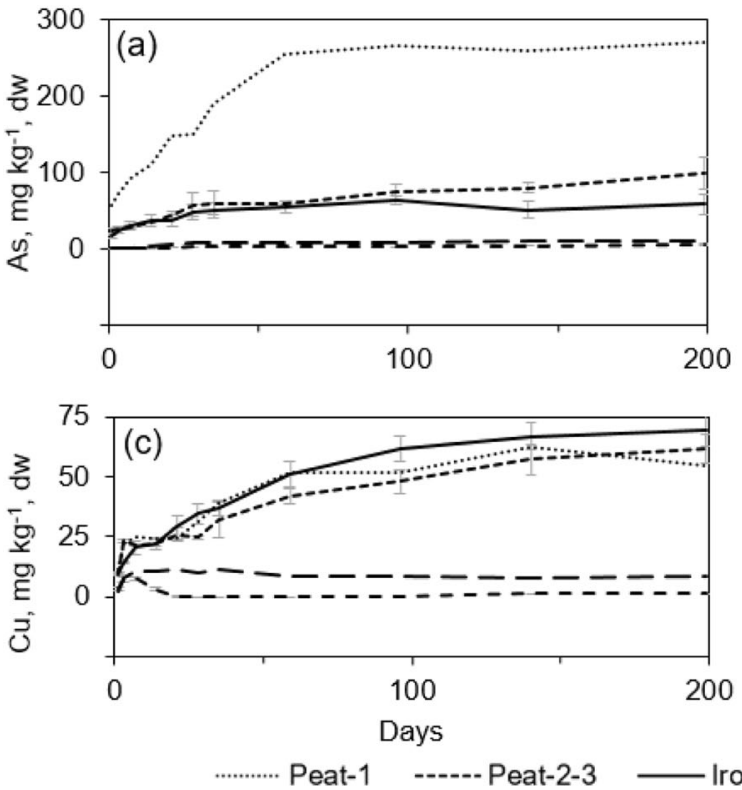

Fig. 3 Metal (loid) leaching from spent sorbents throughout the low redox experiment. Peat-1, single replicate at reducing conditions; peat$2-3$, average of two replicates at oxidising conditions; iron-peat, average of triplicate at reducing conditions; iron-sand-1-2, average of two
The amount of $\mathrm{Cu}$ leached (Fig. 3c) from spent peat and iron-peat was very similar throughout all experiments, and the presence of $\mathrm{O}_{2}$ in the sample had no large effect on $\mathrm{Cu}$ leaching. However, $\mathrm{Cu}$ concentrations in the leachates
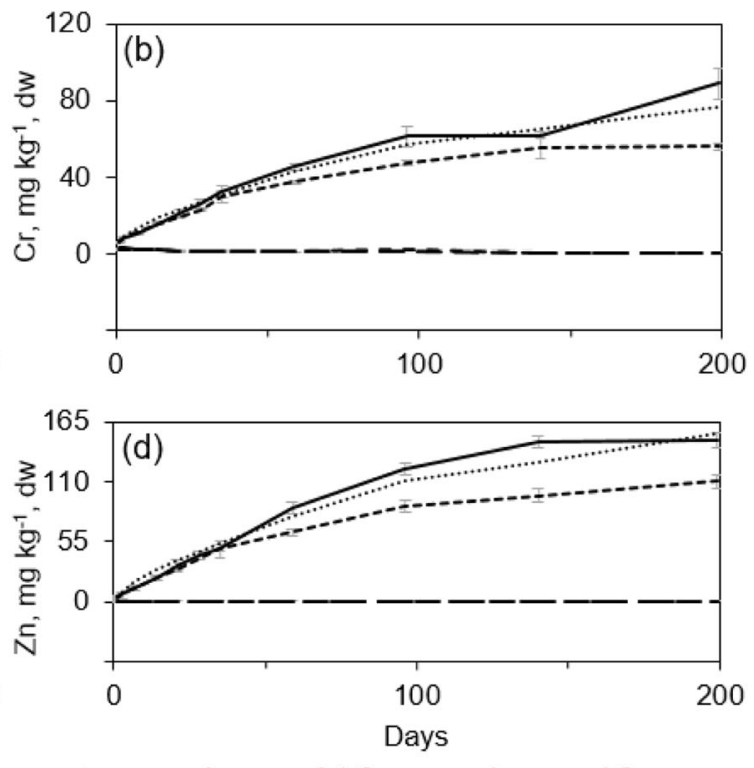

ron-peat $\quad---$ Iron-sand-1-2 - - Iron-sand-3

replicates at oxidising conditions; iron-sand-3, single replicate at reducing conditions. Error bars represent the standard deviation of the mean $(n=2-3)$ 
continually increased, and after 50 days, the $\mathrm{Cu}$ concentration exceeded the limit of non-hazardous waste landfills. In the case of iron-sand, $\mathrm{Cu}$ concentrations in leachates remained at the same level throughout the experiment; however, the $\mathrm{Cu}$ concentration in the leachate from iron-sand-3 was up to seven times higher than those for iron-sand- 1 and -2 , and more than $3 \%$ of the adsorbed $\mathrm{Cu}$ was leached out from iron-sand at reducing conditions.

Leaching of Zn (Fig. 3d) from spent peat-based sorbents increased throughout all experiments, and after 50 days, the $\mathrm{Zn}$ concentration in leachates had already exceeded the limit of non-hazardous waste landfills. Reducing conditions had no effect on $\mathrm{Zn}$ leaching, but if based on $\mathrm{Zn}$ leaching only, spent iron-sand could be considered suitable for disposal at landfills for inert waste.

In the case of spent peat at reducing conditions (peat-1), $1.7 \%$ of $\mathrm{Fe}$ had been leached out at the end of the experiment and $\mathrm{Fe}$ concentrations in the leachate had gradually increased. Approximately $1.4 \%$ of $\mathrm{Fe}$ leached out from peat -2 and -3 during the first 50 days, and the levels remained the same level for the continued duration. Iron-peat had a manifold higher $\mathrm{Fe}$ content compared with the peat sorbent, but only $0.52 \%$ of $\mathrm{Fe}$ had leached out by the end of the experiment. However, Fe concentration in the leachates constantly increased. Iron concentrations in leachates from spent iron-sand were minimal and remained below $0.01 \%$ of the total Fe content.

\section{Speciation of As}

Arsenic speciation was determined in the leachates, which were obtained after completing the standardised batch leaching test and after the final low redox experiment sampling. Both MMA and DMA were found to be below the detection limit in all samples. Concentrations of As (III) and As (V) are presented in Table 5.

At reducing conditions (peat-1), As (III) corresponded to approximately $33 \%$ of all the detected As species. However, in the presence of $\mathrm{O}_{2}$ (peat-2, -3), the As (III) concentration was below the detection limit and only $\mathrm{As}(\mathrm{V})$ was detected. In iron-peat samples, the amount of As (III) corresponded to approximately $30 \%$ of all determined As species.

The reducing conditions had no significant effect on As speciation in iron-sand samples. Arsenate was dominant in the leachates, and the concentration of As (III) was below the detection limits.

\section{Discussion}

\section{Efficiency of sorbents}

Adsorbents used to clean metal (loid) contaminated water need to be efficient and sustainable, which means that the cost
Table 5 Speciation of As in the leachates $\left(\mathrm{mg} \mathrm{kg}^{-1}\right.$, dw) after standardised batch leaching test and low redox experiment \pm standard deviation if possible $(n=2-3)$

\begin{tabular}{|c|c|c|}
\hline \multirow[t]{2}{*}{ Material } & \multicolumn{2}{|c|}{ Concentration of species } \\
\hline & As (III) & $\mathrm{As}(\mathrm{V})$ \\
\hline \multicolumn{3}{|c|}{ Standardised batch leaching test, $\mathrm{L} / \mathrm{S}=10$} \\
\hline Peat & $2.53 \pm 0.27$ & $6.18 \pm 4.47$ \\
\hline Iron-peat & $1.57 \pm 1.19$ & $3.29 \pm 2.22$ \\
\hline Iron-sand & $<0.001$ & $0.069 \pm 0.009$ \\
\hline \multicolumn{3}{|c|}{ Low redox experiment } \\
\hline Peat- $1^{\mathrm{a}}$ & 18.6 & 37.3 \\
\hline Peat- $2,-3^{b}$ & $<0.001$ & $61.7 \pm 36.1$ \\
\hline Iron-peat ${ }^{c}$ & $7.84 \pm 0.39$ & $18.4 \pm 5.7$ \\
\hline Iron-sand-1, $-2^{\mathrm{d}}$ & $<0.001$ & $0.274 \pm 0.056$ \\
\hline Iron-sand- $3^{\mathrm{e}}$ & $<0.001$ & 0.178 \\
\hline
\end{tabular}

${ }^{\text {a }}$ Single replicate at reducing conditions

${ }^{\mathrm{b}}$ Average of two replicates at oxidising conditions

${ }^{\mathrm{c}}$ Average of triplicate at reducing conditions

${ }^{\mathrm{d}}$ Average of two replicates at oxidising conditions

${ }^{\mathrm{e}}$ Single replicate at reducing condition

of treatment should be balanced to provide both environmental and social benefits. Replacing virgin materials with residual materials when producing adsorbents increases the sustainability of the treatment. Therefore, adsorption onto lowcost particulate media, such as peat waste, is an attractive and inexpensive option for removing dissolved metals, especially divalent cations (Brown et al. 2000). At least $100 \mathrm{kt}$ of peat is produced every year in Sweden (Statistics Sweden 2014), and this is mainly used in the production of electricity and energy, agriculture, horticulture, and water filtration. Peat residue is mainly obtained while milling, pelletising, and making briquettes from sod peat. However, as it usually exists as a fine powder, it is difficult to use this waste material again in the production line, as fine powders are difficult to handle and create dust problems. Nevertheless, utilising peat residuals as sorbents would decrease the volume of waste that needs management.

The heat-treated peat used in this study shows a strong potential for adsorbing divalent metal cations from contaminated solution. In the column adsorption experiment, the sorption capacity of $\mathrm{Cu}$ onto peat remained $>99 \%$ after processing approximately $312 \mathrm{BV}$ of the contaminated solution, which indicates that the sorbent's potential towards $\mathrm{Cu}$ had not been exhausted. It is considered that the favourable $\mathrm{pH}$ of around 5 in the metal (loid) solution is the likely reason for the efficient adsorption of $\mathrm{Cu}$ by peat (Ho et al. 1994). However, although the average sorption capacity of $\mathrm{Zn}$ onto peat was $102 \mathrm{mg} \mathrm{Zn} \mathrm{kg}^{-1}$ sorbent, the sorbent started to become exhausted after processing $165 \mathrm{BV}$ of the contaminated 
solution. There could be two possible explanations for this: first, the efficient adsorption of $\mathrm{Zn}$ on peat occurs at a $\mathrm{pH}$ range of 7-9 (Brown et al. 2000), and the contaminated solution used in the column adsorption experiment had a $\mathrm{pH}$ of about 5 , which could be too low for substantial formation of carboxylate complexes with Zn (Bonnet and Cousins 1987). Second, it has been reported that competitive adsorption occurs between $\mathrm{Cu}$ and $\mathrm{Zn}$ ions for adsorption sites on peat (Duran-Jimenez et al. 2016).

The effective adsorption of $\mathrm{Cr}$ (VI) species onto peat is known to be around $\mathrm{pH} 1.5-3.0$, and the effectiveness decreases with an increase in the $\mathrm{pH}$ value (Sharma and Forster 1993; Koloczek et al. 2018). In our case, more than $90 \%$ of inlet $\mathrm{Cr}$ was adsorbed onto peat-based sorbents at a $\mathrm{pH}$ of about five throughout the column adsorption experiment. From the decreasing Eh values that were determined in leachates during the column adsorption experiment (Table 2), it can be assumed that $\mathrm{Cr}$ (VI) was reduced to $\mathrm{Cr}$ (III). This observation was confirmed by the $\mathrm{Cr}$ speciation analysis, when a significant part of $\mathrm{Cr}$ in eluates towards the end of column experiment was determined as $\mathrm{Cr}$ (III). At a $\mathrm{pH}$ of above 3.7, the predominant species of $\mathrm{Cr}$ (III) are positively charged ions, $\mathrm{Cr}^{3+}$, which are mostly adsorbed onto hydroxylic groups present on the surface of peat (Koloczek et al. 5). In this respect, a $\mathrm{pH}$ range of 4.0-5.5 is the most favourable for efficient $\mathrm{Cr}$ (III) adsorption onto peat (Balan et al. 2009).

Adsorption of As onto peat was weaker than $\mathrm{Cr}, \mathrm{Cu}$, and $\mathrm{Zn}$. Although, peat adsorbed nearly $50 \%$ of inlet As throughout the column adsorption experiment, a rapid loss of efficiency was observed after 3 days. The interaction between As and natural organic matter is a complex process and scientific literature provides several hypothesis about such binding mechanisms. For example, it is hypothesised that As can form covalent carbon-As bonds directly with organic matter (Buschmann et al. 2006) or through organic functional groups, such as hydroxyl groups (Warwick et al. 2005). It is widely suggested that metal cations (e.g. Fe) act as bridges between As and organic matter, forming ternary complexes (e.g. Mikutta and Kretzschmar 2011; Mak and Lo 2011). However, in Sundman (2014) and Sundman et al. (2015), it is stated that it is hard to find spectroscopic evidence for the existence of $\mathrm{As}(\mathrm{V})-\mathrm{Fe}$ (III)-organic matter complexes even at high $\mathrm{Fe}$ and As concentrations.

In this study, the adsorption of As substantially increased when peat particles were coated with Fe. This increased adsorption of As onto iron-peat can be explained by the increase in the specific surface area (obtained by the BET method), which is one of the most important factors affecting sorption; the specific surface of iron-peat was by 1.8 times higher than uncoated peat. Furthermore, As has a high affinity for interacting with $\mathrm{Fe}$ hydroxides, and it is thus obvious that the sorbent with the highest $\mathrm{Fe}$ content and the largest specific surface area would have the highest As adsorption potential.
However, the adsorption of $\mathrm{Cr}, \mathrm{Cu}$, and $\mathrm{Zn}$ onto iron-peat was slightly lower (up to $10-15 \%$ ) than that of peat, and it is likely that coating peat with $\mathrm{Fe}$ resulted in blocking some of the organic groups. Nevertheless, the removal of cations remained within an acceptable range.

Iron-sand had a lower specific surface area than iron-peat. However, although the $\mathrm{Fe}$ content was also lower in iron-sand ( $3.25 \mathrm{~g} \mathrm{~kg}^{-1}$ vs $\left.5.60 \mathrm{~g} \mathrm{~kg}^{-1}\right)$, the sorption capacity was similar to that of iron-peat. Nevertheless, the lack of organic material that could provide cation exchange sites resulted in the very weak adsorption of $\mathrm{Cr}, \mathrm{Cu}$, and $\mathrm{Zn}$.

In summary, Fe-coated peat sorbent showed properties that ensure a high sorption potential, and it could thus be effective for the simultaneous removal of metal (loid)s. These results agree with those of our previous study (Kasiuliene et al. 2018), where it was pointed that adjusting the $\mathrm{pH}$ to the target contaminant could provide even higher removal capacity.

The modification of peat with $\mathrm{Fe}$ compounds has gained considerable scientific attention in recent years (Ansone et al. 2012; Oliveira et al. 2015). In addition to removing As, the increased sorption of $\mathrm{V}$ group metalloids, such as antimony and tellurium, by Fe-modified peat sorbents has also been reported (Ansone and Klavins 2016). In contrast, the possibility of using waste-derived $\mathrm{Fe}$ sources for coating peat has seldom been discussed. Two million tonnes of Fe waste was produced in Sweden in 2015, and although the largest proportion is reused as raw material, approximately $20 \%$ is landfilled (Jernkontoret 2012). Therefore, using waste materials rich in Fe to coat peat (also waste-based) would not only reduce the need to use virgin materials, but also would reduce the volume of waste intended for landfill.

\section{Landfilling spent sorbents}

One of the main questions that arises when discussing adsorption is what management strategies should be applied with respect to the spent sorbent. However, the management and regeneration of spent sorbents are seldom addressed. If the sorbent is used to adsorb oxyanion forming elements, such as As, regeneration techniques are limited and/or expensive (Verbinnen et al. 2015), and as As has a limited market, its recovery is not preferred. Thus, landfilling As-containing wastes has been the predominant management choice.

Iron-sand in this study was used as a control sorbent for iron-peat. As shown in the column adsorption experiment, both of the Fe-bearing sorbents adsorbed As to a similar extent. However, due to its large inert carrier proportion, ironsand generates a considerable amount of spent sorbent. Because it could be disposed of at landfills for hazardous waste (based on the results from the standardised batch leaching test), and considering that the VS content in the iron-sand was $<1 \%$, landfilling could be the most reasonable final sink. 
In contrast with iron-sand, peat-based sorbents had a high VS content (up to 93\%). However, landfilling waste with a high organic loading can cause the undesirable production of landfill gases, and the negative impact of landfill gas on the greenhouse effect, which has been much addressed in scientific literature (e.g. Lou and Nair 2009). For this reason, waste with more than $10 \%$ of organic content is not accepted at landfills in Europe. In certain circumstances, when type of waste does not fulfil the acceptance criteria, determined in the Council Directive 1999/31/EC, Annex II, and there is no other viable utilisation option, landfilling can be allowed if special permit is acquired. In this case, it is crucial to evaluate degradability of such waste under anaerobic conditions. In this study, BMP test, performed with spent peat and iron-peat, showed that gas production was supressed compared with the control inoculum samples. Microorganisms that are involved in anaerobic processes are sensitive not only to toxic metal (loid) s such as As, lead (Pb), or cadmium (Cd), but also to excessive doses of essential microelements, such as $\mathrm{Cr}, \mathrm{Cu}$, and $\mathrm{Zn}$ (Mudhoo and Kumar 2013). Furthermore, the DOC values in the leachates from peat-based spent sorbents were below the limit values for non-hazardous landfill wastes. Therefore, landfilling such waste would not contribute to the potential risks often related to highly biodegradable waste.

Based on the results of standardised batch leaching test, spent iron-peat could be disposed of in hazardous waste landfills. However, as the concentration of As in the leachates from spent peat was found to be above the limits for hazardous waste landfills, the spent sorbent needs to be pre-treated prior to landfilling. Although thermally treating As-rich waste is complicated, because volatilisation of As can start at temperatures as low as $320^{\circ} \mathrm{C}$ (Helsen et al. 2003), fabric filters and electrostatic precipitators (that are present in modern waste incineration plants) can remove more than $99 \%$ of particulate matter (Jones and Harrison 2016). Given the high organic matter content present in spent peat-based sorbents, thermal treatment coupled with energy recovery could thus be a viable option.

The standardised batch leaching test showed that As mostly exceeded guideline limits in all three sorbents (Table 3). During the test, ultra-pure water was used as a leachant and aerobic conditions prevailed. However, landfills normally have anaerobic conditions. The mobility of metal (loid) $\mathrm{s}$ is governed not only by $\mathrm{pH}$ and the availability of sorption sites present in the system, but also by redox conditions, and the Eh in a landfill can drop as low as $-500 \mathrm{mV}$ (Bozkurt et al. 2000). During the low redox experiment, it was possible to obtain Eh value only as low as $47.7 \pm 8.9 \mathrm{mV}$ (Fig. 2b, e, h). However, the mobility of redox-sensitive As was substantially affected by the decreasing Eh values. At reducing conditions, $60 \%$ of adsorbed As leached out from spent peat (peat-1), and 'only' $22 \%$ leached out during oxidising conditions (peat-2, 3 ). The several-fold increase in As leaching occurred because
$\mathrm{As}(\mathrm{V})$ is reduced to a more mobile and toxic As (III) at reducing environment (Corvin et al. 1999). This is consistent with analysis conducted for As speciation (Table 5). Arsinite was undetectable during oxidising conditions, but more than $30 \%$ of total detected As was present as As (III) at reducing conditions. During the low redox experiment, leaching of As from Fe-bearing spent sorbents was significantly lower compared with from spent peat, and the same behaviour was observed during the standardised batch leaching test. These results indicate that reductive dissolution of the main As-bearing phases (Fe-Mn oxides), which is largely responsible for As being released back to the leachate (Kumpiene et al. 2009), was slower when the Fe concentration of the sorbent was higher.

The amount of As leached from the spent iron-peat during the low redox experiment exceeded the acceptable limit at landfills for hazardous waste. This outcome is different from the one obtained after the standardised batch leaching test. The low redox experiment lasted 200 days, and the prevailing reducing atmosphere may have caused decomposition of organic matter complexes (Bozkurt et al. 2000; Mikutta and Kretzschmar 2011), possibly involving As as well. Only 6\% of the adsorbed As leached out from the spent iron-peat but considering that iron-peat adsorbed $1.01 \mathrm{~g} \mathrm{As} \mathrm{kg}^{-1}$, treatment of the leachate could become difficult. It would thus be necessary to pre-treat the spent iron-peat as well.

Iron-sand adsorbed slightly more than $0.12 \mathrm{~g} \mathrm{As} \mathrm{kg}^{-1}$ sorbent during the column adsorption test. However, although, nearly $8 \%$ of the adsorbed As leached out during the low redox experiment, the spent sorbent could still be considered a hazardous waste. However, as the As concentration in the leachate gradually increased over the time, increased concentrations of As would eventually be released into the leachate due to the dissolution of Fe hydroxides induced by the decreasing Eh.

The importance of microbial reduction of Fe hydroxides and thus the release of As cannot be ruled out in a full-scale landfill. Furthermore, the Eh in landfill can drop much lower than the value it reached during the low redox experiment, which would thus complicate treatment of the leachate.

The mobility of many other toxic metal (loid) s, including $\mathrm{Cr}, \mathrm{Cu}$, and $\mathrm{Zn}$, is usually low under conditions generally found in mature landfills (Bozkurt et al. 2000). Therefore, based on $\mathrm{Cr}, \mathrm{Cu}$, and $\mathrm{Zn}$, leaching during the standardised batch leaching test, spent peat, and iron-peat could be deposited of at inert waste landfills. However, leaching of these elements increased over prolonged contact with the leachant during the low redox experiment, and in the case of $\mathrm{Cu}$ and $\mathrm{Zn}$, classification of landfill type shifted from the inert towards the hazardous landfill type. In addition, leaching of $\mathrm{Cr}$ during the low redox experiment exceeded the limit values for hazardous waste landfills, and there was also an increased leaching tendency of $\mathrm{Cr}, \mathrm{Cu}$, and $\mathrm{Zn}$. Hydrolysis of organic 
matter, in particular hydroxylic groups, possibly occurring on the surface of peat (Koloczek et al. 5), may have caused desorption of positively charged $\mathrm{Cr}$ (III), $\mathrm{Cu}$ and $\mathrm{Zn}$.

\section{Concluding remarks}

Peat effectively adsorbed $\mathrm{Cr}, \mathrm{Cu}$, and $\mathrm{Zn}$, whereas approximately $50 \%$ of inlet As was detected in the eluent. Iron-sand was effective only for adsorbing $\mathrm{As}$, but $\mathrm{Cr}, \mathrm{Cu}$, and $\mathrm{Zn}$ were poorly adsorbed. Only iron-peat showed the simultaneous removal of all tested metal (loid)s. Therefore, a combination of two active sorbents, peat and $\mathrm{Fe}$, is necessary for a single-step adsorption process. In addition, it would be beneficial to use waste-based materials to prevent the use of virgin materials in making the iron-peat sorbent and reduce the volume of waste intended for landfilling.

Leaching of As was a decisive factor in determining the landfill type for the spent sorbents. Based on the standardised batch leaching test, spent iron-peat and iron-sand sorbents could be disposed of at hazardous waste landfills. However, oxidising conditions, which prevailed during the standardised batch leaching test, could have led to an underestimation of redoxsensitive As leaching. Substantially higher amounts of As leached out from the spent sorbents at reducing atmosphere compared with the oxidising one. Furthermore, the reducing conditions caused $\mathrm{As}(\mathrm{V})$ to be reduced to the more-toxic As (III): therefore, the potential of increased amounts of $\mathrm{As}(\mathrm{V})$ and As (III) occurring in the landfill leachate is high. Decreasing Eh potential affected leaching of $\mathrm{Cr}, \mathrm{Cu}$, and $\mathrm{Zn}$ to a lesser extent.

Funding information This study was financially supported by the Swedish Research Council Formas (ID 942-2015-873), the Eurostars-2 Joint Programme with co-funding from the European Union Horizon 2020 Research and Innovation Programme, and the EU Structural Funds project Green North. The Wallenberg Foundation and the Åforsk Foundation are also acknowledged for their financial support.

Open Access This article is distributed under the terms of the Creative Commons Attribution 4.0 International License (http:// creativecommons.org/licenses/by/4.0/), which permits unrestricted use, distribution, and reproduction in any medium, provided you give appropriate credit to the original author(s) and the source, provide a link to the Creative Commons license, and indicate if changes were made.

\section{References}

Ahmad A, Richards LA, Bhattacharya P (2017) Arsenic remediation of drinking water: an overview. In: Bhattacharya P, Polya DA, Jovanovic D (eds) Best practice guide on the control of arsenic in drinking water. Metals and related substances in drinking water series. IWA Publishing, UK, pp 79-98. https://doi.org/10.2166/ 9781780404929 079
Ansone L, Klavins M (2016) Sorption of V and VI group metalloids (As, $\mathrm{Sb}, \mathrm{Te})$ on modified peat sorbents. Open Chem 14:46-59. https:// doi.org/10.1515/chem-2016-0003

Ansone L, Klavins M, Robalds A, Viksna A (2012) Use of biomass for removal of arsenic compounds. Latv J Chem 51(4):324-335. https:// doi.org/10.2478/v10161-012-0018-7

Balan C, Bilba D, Macoveanu M (2009) Studies on chromium (III) removal from aqueous solution by sorption on Sphagnum moss peat. J Serb Chem Soc 74:953-964. https://doi.org/10.2298/JSC0909953B

Bhattacharya P, Mukherjee AB, Jacks G, Nordqvist S (2002) Metal contamination at a wood preservation site: characterisation and experimental studies on remediation. Sci Total Environ 290:165-180

Bonnet R, Cousins RPC (1987) On the metal content and metal ion uptake of botanically specific peat and the derived humic acids. Org Geochem 11:497-503

Bozkurt S, Moreno L, Neretnieks I (2000) Long-term processes in waste deposits. Sci Total Environ 250:101-121

Brown PA, Gill SA, Allen SJ (2000) Metal removal from wastewater using peat. Water Res 34:3907-3916. https://doi.org/10.1016/ S0043-1354(00)00152-4

Buschmann J, Kappeler A, Lindauer U, Kistler D, Berg M, Sigg L (2006) Arsenite and arsenate binding to dissolved humic acids: influence of $\mathrm{pH}$, type of humic acid, and aluminium. Environ Sci Technol 40: 6015-6020. https://doi.org/10.1021/es061057

Callegari A, Ferronato N, Rada EC, Capodaglio AG, Torretta V (2018) Assessment of arsenic removal efficiency by an iron oxide-coated sand filter process. Environ Sci Pollut Res 25:26135-26143. https:// doi.org/10.1007/s11356-018-2674-y

Carabante I, Mouzon J, Kumpiene J, Gran M, Fredriksson A, Hedlund J (2014) Reutilization of porous sintered hematite bodies as effective adsorbents for arsenic $(\mathrm{V})$ removal from water. Ind Eng Chem Res 53:12689-12696. https://doi.org/10.1021/ie500919d

Chaney RL, Hundemann PT (1979) Use of peat moss columns to remove cadmium from wastewaters. J Water Pollut Control Fed 51:105-114

Corvin DL, David A, Goldberg S (1999) Mobility of arsenic in soil from the Rocky Mountain Arsenal area. J Contam Hydrol 39:35-58

Council Decision 2003/33/EC: establishing criteria and procedures for the acceptance of waste at landfills pursuant to Article 16 of and Annex II to Directive 1999/31/EC

Council Directive 1991/31/EC: on the landfill of waste

Devi RR, Umlong IR, Das B, Borah K, Thakur AJ, Raul PK, Banerjee S, Singh L (2014) Removal of iron and arsenic (III) from drinking water using iron oxide-coated sand and limestone. Appl Water Sci 4:175-182. https://doi.org/10.1007/s13201-013-0139-5

Duran-Jimenez G, Hernandez-Montoya V, Montes-Moran MA, RangelMendez JR, Tovar-Gomez R (2016) Study of the adsorptiondesorption of $\mathrm{Cu}^{2+}, \mathrm{Cd}^{2+}$ and $\mathrm{Zn}^{2+}$ in single and binary aqueous solutions using oxygenated carbons prepared by Microwave Technology. J Mol Liq 220:855-864. https://doi.org/10.1016/j. molliq.2016.05.027

Hagner M, Romantschuk M, Penttinen OP, Egfors A, Marchand C, Augustsson A (2018) Assessing toxicity of metal contaminated soil from glassworks sites with a battery of biotests. Sci Total Environ 613-614:30-38. https://doi.org/10.1016/j.scitotenv.2017.08.121

Hausladen DM, Fendorf S (2017) Hexavalent chromium generation within naturally structured soils and sediments. Environ Sci Technol 51: 2058-2067. https://doi.org/10.1021/acs.est.6b04039

Helsen L, Van den Bulck E, Van Bael MK, Mullens J (2003) Arsenic release during pyrolysis of CCA treated wood waste: current state of knowledge. J Anal Appl Pyrolysis 68-69:613-633. https://doi.org/ 10.1016/s0165-2370(03)00055-x

Ho YS, Wase DAJ, Forster CF (1994) The adsorption of divalent copper ions from aqueous solution by Sphagnum moss peat. Process Saf Environ 72b:185-194

Jambeck JR, Townsend TG, Solo-Gabriele HM (2008) Landfill disposal of CCA-treated wood with construction and demolition (C\&D) 
debris: arsenic, chromium, and copper concentrations in leachate. Environ Sci Technol 42:5740-5745

Jernkontoret (2012) The steel eco-cycle. Scientific report 2004-2012. https://www.jernkontoret.se/en/. Accessed 09 January 2019

Jones AM, Harrison RM (2016) Emission of ultrafine particles from the incineration of municipal solid waste: a review. Atmos Environ 140: 519-528. https://doi.org/10.1016/j.atmosenv.2016.06.005

Kasiuliene A, Carabante I, Bhattacharya P, Caporale AG, Adamo P, Kumpiene J (2018) Removal of metal (oid) s from contaminated water using iron-coated peat sorbent. Chemosphere 198:290-296. https://doi.org/10.1016/j.chemosphere.2018.01.139

Koloczek H, Jaroslaw C, Zukowski W (2015) Peat and coconut fibre as biofilters for chromium adsorption from contaminated wastewaters. Environ Sci Pollut Res 23:527-534. https://doi.org/10.1007/ s11356-015-5285-x

Kumpiene J, Ragnvaldsson D, Lovgren L, Tesfalidet S, Gustavsson B, Lattstrom A, Leffler P, Maurice C (2009) Impact of water saturation level on arsenic and metal mobility in the Fe-amended soil. Chemosphere 74:206-215. https://doi.org/10.1016/j.chemosphere. 2008.09.068

Langner P, Mikutta C, Suess E, Marcus MA, Kretzschmar R (2013) Spatial distribution and speciation of arsenic in peat studied with Microfocused X-ray fluorescence spectrometry and X-ray absorption spectroscopy. Environ Sci Technol 47:9706-9714. https://doi. org/10.1021/es401315e

Lou XF, Nair J (2009) The impact of landfilling and composting on greenhouse gas emissions - a review. Bioresour Technol 100: 3792-3798. https://doi.org/10.1016/j.biortech.2008.12.006

Lov A, Sjosted C, Larsbo M, Persson I, Gustafsson JP, Cornelis G, Kleja DB (2017) Solubility and transport of Cr (III) in a historically contaminated soil- evidence of a rapidly reacting dimeric $\mathrm{Cr}$ (III) organic matter complex. Chemosphere 189:709-716. https://doi.org/ 10.1016/j.chemosphere.2017.09.088

Mak MS, Lo IM (2011) Influences of redox transformation, metal complexation and aggregation of fulvic acid and humic acid on $\mathrm{Cr}$ (VI) and $\mathrm{As}(\mathrm{V})$ removal by zero-valent iron. Chemosphere 84:234-240. https://doi.org/10.1016/j.chemosphere.2011.04.024

Mikutta C, Kretzschmar R (2011) Spectroscopic evidence for ternary complex formation between arsenate and ferric iron complexes of humic substances. Environ Sci Technol 45:9550-9557. https://doi. org/10.1021/es202300w

Mohan D, Pittman CU (2007) Arsenic removal from water/wastewater using adsorbents - a critical review. J Hazard Mater 142:1-53. https://doi.org/10.1016/j.jhazmat.2007.01.006

Mondal MK, Garg R (2017) A comprehensive review on removal of arsenic using activated carbon prepared from easily available waste materials. Environ Sci Pollut Res 24:13295-13306. https://doi.org/ $10.1007 / \mathrm{s} 11356-017-8842-7$

Mudhoo A, Kumar S (2013) Effects of heavy metals as stress factors on anaerobic digestion processes and biogas production from biomass.
Int J Environ Sci Technol 10:1383-1393. https://doi.org/10.1007/ s13762-012-0167-y

Oliveira KL, Melo CA, Goveia D, Lobo FA, Hernandez MAA, Fraceto LF, Rosa AH (2015) Adsorption/desorption of arsenic by tropical peat: influence of organic matter, iron and aluminium. Environ Technol 36:149-159. https://doi.org/10.1080/03650340.2015. 1096015

Sharma DC, Forster CF (1993) Removal of hexavalent chromium using sphagnum moss peat. Water Res 27:1201-1208. https://doi.org/10. 1016/0043-1354(93)90012-7

Statistics Sweden (2014) Production, use and environmental impact: peat use in energy production has decreased five years in a row. Statistical news from Statistics Sweden and Swedish Energy Agency. https://www.scb.se/en/. Accessed 09 January 2019

Stepanova VA, Pokrovsky OS, Viers J, Mironycheva-Tokareva NP, Kosykh NP, Vishnyakova EK (2015) Elemental composition of peat profiles in western Siberia: effect of the micro-landscape, latitude position and permafrost coverage. Appl Geochem 53:53-70. https:// doi.org/10.1016/j.apgeochem.2014.12.004

Sundman A. (2014) Interactions between Fe and organic matter and their impact on $\mathrm{As}(\mathrm{V})$ and $\mathrm{P}(\mathrm{V})$. Dissertation, Umeå University

Sundman A, Karlsson T, Persson P (2015) Reactivity of Fe from a natural stream water towards as(V). Appl Geochem 61:185-191. https:// doi.org/10.1021/es401193j

Theis TL, Iyer R, Ellis SK (1992) Evaluating a new granular iron oxide for removing lead from drinking water. J Am Water Works Assoc 84:101-105

Verbinnen B, Block C, Caneghem J, Vandecasteele C (2015) Recycling of spent adsorbents for oxyanions and heavy metal ions in the production of ceramics. Waste Manag 45:409-411. https://doi.org/10. 1016/j.wasman.2015.07.006

Wang Y, Sun L, Han T, Si Y, Wang R (2017) Arsenite and arsenate leaching and retention on iron (hydr)oxide-coated sand column. J Soils Sediment 16:486-496. https://doi.org/10.1007/s11368-0151230-3

Warwick P, Inam E, Evans N (2005) Arsenic's interaction with humic acid. Environ Chem 2:119-124. https://doi.org/10.1071/EN05025

World Health Organization (2017) Guidelines for drinking-water quality: fourth edition incorporating the first addendum. Geneva

Yurum A, Kocabas-Atakli ZO, Sezen M, Semiat R, Yurum Y (2014) Fast deposition of porous iron oxide on activated carbon by microwave heating and arsenic (V) removal from water. Chem Eng J 15:321332. https://doi.org/10.1016/j.cej.2014.01.005

Publisher's note Springer Nature remains neutral with regard to jurisdictional claims in published maps and institutional affiliations. 